\title{
Common physiological responses during TTM
}

\author{
Guillaume Geri $^{1,2,3^{*}}$, Benoit Champigneulle ${ }^{1,2,3}$, Wulfran Bougouin ${ }^{1,2,3}$, Michel Arnaout ${ }^{1,2,3}$, Alain Cariou ${ }^{1,2,3}$ \\ From Targeted Temperature Management (TTM 2014) \\ Berlin, Germany. 6-7 November 2014
}

Achieving and maintaining perfect homeostasis, particularly in terms of metabolism, represent a major goal for post-cardiac arrest (CA) care. Since cooling may provoke different physiological responses, it is of particular importance to be aware of these changes that may require specific treatment adjustments during this recovery period [1]. Several points are particularly illustrative. Regarding ventilatory management, induced therapeutic hypothermia (TH) is known to decrease $\mathrm{CO}_{2}$ production, which may result in deleterious hypocapnia. Blood gases and expiratory tidal $\mathrm{CO}_{2}$ should be cautiously monitored in order to adapt ventilator settings since pronounced hypocapnia can provoke a decrease in cerebral blood flow that may alter brain perfusion [2]. Conversely, hypercapnia, leading to cerebrovascular vasodilatation and increased intracranial pressure, should also be banned. Regarding metabolic control, the correction of electrolyte and acid-base disturbances is essential and special attention should be given to those that may participate in the recurrence of CA or worsening of organ dysfunction (potassium, arterial $\mathrm{pH}$ ). Concerning glycemia, consistent data underline that blood glucose variability seriously impairs the outcome of these patients rather than the mean level of glycemia, so attention should be paid to avoid such glycemia fluctuations [3]. Besides severe shock and brain injuries, patients with successfully resuscitated $\mathrm{CA}$ are also exposed to infectious complications, a supplementary insult which may affect a large number of survivors. Experimental hypothermia impairs immune functions and inhibits the secretion of proinflammatory cytokines and may suppress leukocyte migration and phagocytosis. In humans, $\mathrm{TH}$ is associated with an increased risk of early onset pneumonia [4]. Furthermore, the diagnosis of these infectious events is complicated in patients after CA, not only by the physiological effects of $\mathrm{TH}$ but also by the consequences of postcardiac arrest syndrome. Even if they do not impact on survival or neurological outcome, these infectious events increase the duration of mechanical ventilation and hospital length of stay and should be managed using tailored preventive and therapeutic strategies. Finally, TH might also induce physiological changes in coagulation that may promote acute stent thrombosis. Experimental models showed that hypothermia may induce platelet activation, thrombus formation and stabilization, and several clinical studies reported an unexpected high rate of acute stent thrombosis in cardiac arrest patients after cooling for CA, which may compromise the benefit associated with early coronary reperfusion [5]. On the whole, being aware of all physiological changes induced by $\mathrm{TH}$ is crucial in order to maximize the benefit of this treatment in clinical practice.

\section{Financial disclosure}

AC has received honorarium and/or travel costs from C. R. BARD and from Lilly France.

\section{Declaration}

This abstract and supplement was proposed, developed and commissioned by BMC Emergency Medicine and was funded by an educational grant from C. R. BARD, NJ, USA. The published abstract was independently prepared by the author. C. R. BARD had no input into the content.

\section{Authors' details}

${ }^{1}$ Medical Intensive Care Unit, AP-HP, Cochin Hospital, Paris, France. ${ }^{2}$ Paris Descartes University - Medical School, Paris, France. ${ }^{3}$ INSERM U970, Cardiovascular Research Center, European Georges Pompidou Hospital, Paris, France.

Published: 24 June 2015

\section{References}

1. Neumar RW, Barnhart JM, Berg RA, Chan PS, Geocadin RG, Luepker RV, et al: Implementation strategies for improving survival after out-of-hospital cardiac arrest in the United States: consensus recommendations from the 2009 American Heart Association Cardiac Arrest Survival Summit. Circulation 2011, 123:2898-910.

2. Sandroni C, D'Arrigo S: Management of oxygen and carbon dioxide pressure after cardiac arrest. Minerva Anestesiol 2014, 80:1105-14.

3. Cueni-Villoz N, Devigili A, Delodder F, Cianferoni S, Feihl F, Rossetti AO, et al: Increased blood glucose variability during therapeutic hypothermia and outcome after cardiac arrest. Crit Care Med 2011, 39:2225-31. 
4. Perbet S, Mongardon N, Dumas F, Bruel C, Lemiale V, Mourvillier B, et al: Early-onset pneumonia after cardiac arrest: characteristics, risk factors and influence on prognosis. Am J Respir Crit Care Med 2011, 184:1048-54

5. Joffre J, Varenne O, Bougouin W, Rosencher J, Mira JP, Cariou A: Stent thrombosis: an increased adverse event after angioplasty following resuscitated cardiac arrest. Resuscitation 2014, 85:769-73.

doi:10.1186/1471-227X-15-S1-A14

Cite this article as: Geri et al: Common physiological responses during TTM. BMC Emergency Medicine 2015 15(Suppl 1):A14.

Submit your next manuscript to BioMed Central and take full advantage of:

- Convenient online submission

- Thorough peer review

- No space constraints or color figure charges

- Immediate publication on acceptance

- Inclusion in PubMed, CAS, Scopus and Google Scholar

- Research which is freely available for redistribution

Submit your manuscript at www.biomedcentral.com/submit
C Biomed Central 